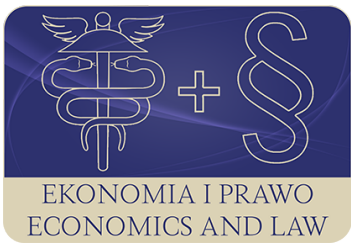

EKONOMIA I PRAWO. ECONOMICS AND LAW

Volume 19, Issue 1, March 2020

p-ISSN 1898-2255, e-ISSN 2392-1625

www.economicsandlaw.pl

ORIGINAL ARTICLE

received 30.03.2019; revised 20.12.2019; accepted 31.03.2020

Citation: Grzeszczyk, T.A., \& Pełszyński, J. (2020). Towards a conceptualization of a social efficiency notion in management sciences. Ekonomia i Prawo. Economics and Law, 19(1): 33-46.

doi:10.12775/EiP.2020.003.

\title{
Towards a conceptualization of a social efficiency notion in management sciences
}

\section{TADEUSZ A. GRZESZCZYK}

corresponding author

Warsaw University of Technology, Faculty of Management, Chair of Management Processes, ul. Narbutta 85, 02-524 Warszawa, Poland

$\square$ tadeusz.grzeszczyk@pw.edu.pl

(iD) orcid.org/0000-0002-4898-1931

\section{JACEK PEESZYŃSKI}

Polish National Health Fund in Warsaw, Poland

$\square$ jacek.pelszynski@nfz.gov.pl

orcid.org/0000-0002-1011-2474

\begin{abstract}
Motivation: In the past, economic efficiency was a key criterion for assessing different types of activities undertaken by various organizations. It has been noticed that acquiring economic efficiency cannot be the only goal, and efficiency notion has many meanings. Processes and projects should be economically effective, at the same time being harmful to different social interests. There are difficulties in understanding and conceptualization of social efficiency notion in management sciences research, and, in particular, in the area of project management.

Aim: This research aims to contribute to filling the gap concerning a conceptualization of a social efficiency notion in management sciences, with particular emphasis on the field of project management.

Results: Achieving paper goal may simplify communication in the scientific community using the social efficiency concept, exchange of scientific information, further work related to operationalization of this concept and development methods for its measurement. Further work on social efficiency evaluation methods may facilitate considerations regarding the transition from the social efficiency notion phase to the concept phase and the idea
\end{abstract}


of using social points for estimating obtained social effects. This opens the way for the development of more objective measurement principles and methods that do not require monetization of social impact, which is now commonly used e.g. in models like Social Return on Investment.

Keywords: efficiency evaluation; social efficiency conceptualization; project management; terminology

JEL: D04; D61; H43; M14; O22

\section{Introduction}

Management is a set of activities (including planning, organizing, motivating and controlling) directed to the resources of organizations (personnel, financial, material, information and knowledge) implemented with the intention of efficient and effective achievement of organization's goals (Griffin, 2015). The effectivity of these activities should be as vast as possible. However, it cannot be based on its classical understanding, focusing only on financial and economic aspects as well as use indicators and tools based on short-term cash flows.

The weaknesses of evaluation based on cash flows, both repeatable processes and unique projects, although seem natural, should be replaced by multi-aspect evaluation systems, methods and tools used to compare the desired effects and inputs, and reflect their diversity, multiplicity and complexity consistent with concepts of: Triple Bottom Line (TBL), Corporate Social Responsibility (CSR) and Sustainable Project Management (Sabini et al., 2019). An overview of research related to the field of sustainability and project management is presented in Toledo et al. (2019).

Such ideas in relation to business management is the integration of economically and socially focused entrepreneurship allowing for solving multicriteria managerial problems using economic assessment indicators that meet the social needs of stakeholders and employees in harmony with existing environmental constraints and the needs of future generations (Pashkevych et al., 2018, p. 148). Approaches of CSR are discussed in more detail in some publications, such as Jankalov \& Jankal (2017) and Krajnakova et al. (2018).

Therefore, it is essential and necessary to develop research on evaluation harmoniously with many criteria for effective planning and implementation of processes and projects that take into account such aspects as responsibility, social equality and inclusion, accountability, empowerment, stable development as well as social and environmental sustainability. The development of this type of research requires a new look at the current achievements in the theory and practice of evaluation and ordering the applied scientific terminology towards better understanding and taking into consideration factors of evaluation of efficiency enabling, for example, assessing the improvement of social well-being and implementing the sustainability concept.

Current approaches to evaluation known in the field of management sciences, often do not sufficiently take into account the study of social effects 
of actions undertaken and may even favor the targeting of socially harmful projects. Regardless of the type of activities and projects being implemented, it is necessary to take care of safety and a friendly, pleasant attitude towards people connected with a given local area. These factors are one of the most important aspects of providing social welfare of the society and also contribute to staying in a given area and connecting their future with it in accordance with the concept of sustainability (Pavlova \& Senfelde, 2017).

Evaluation is carried out in order to reduce the risk of incorrect implementation of projects in conditions of constantly increasing requirements and limited resources. The growth in its importance in management sciences results from the increasing number of organizations using the project approach in their activities, considerable interest from the evaluator practitioners, as well as the rising theoretical study in the field of commercial and public project management.

The efficiency criterion is of fundamental importance when planning and implementing evaluation processes. First of all, it is necessary to take into account its multifaceted nature, which means that its measurement is often a significant challenge. It is not easy to include qualitative aspects, and evaluation of social effects and responsible development cannot be based only on quantitative research. There is a clear research gap related to the methodology of efficiency evaluation in relation to multidimensional aspects of different qualitative and quantitative effects as well as financial and non-financial benefits (Glodzinski, 2018, pp. 731-738).

In the scientific literature, the multifaceted nature of the efficiency notion (Czaplak, 2016) and the need to base on both quantitative and qualitative parameters when estimating it are emphasized. Study of social context of undertaken activities and measurement of changes in the quality of life as a result of implemented public projects require complex and comprehensive measurement methods (Balcerzak \& Pietrzak, 2015).

Efficiency evaluation ought to refer to the comparison of obtained, multifaceted effects of projects in relation to various consumed resources. The obtained effects should not be assessed only financially, but, first of all, in terms of the social effects of undertaken activities, implemented public, development and European projects (Grzeszczyk \& Czajkowski, 2017, pp. 241-246). This kind of efficiency measurement often requires different approaches and methods based on scientific achievements, including more integrated approaches based on multiple goals and constraints (Suter \& Cormier, 2008, pp. 478-485). It is also important to properly select the types of evaluation approaches (formative, summative and developmental) appropriate for the various stages of the project life cycle (Grzeszczyk \& Klimek, 2018, p. 134).

It can be noted that there is a lack of unambiguous and consistent understanding of the social efficiency notion, in particular in the context of project management, which requires focusing on this terminological problem. The social efficiency notion has a multifaceted and interdisciplinary character that results from the wide variety of assessed facilities, the occurrence of various trends 
in scientific research and the ways of taking into consideration environmental influences and external factors.

It is essential to pay more attention to the social efficiency notion, a better explanation of it, as well as its conceptualization on the basis of management sciences. The analysis of the state of the art may be facilitated by the bibliometric analysis that can allow to build the basis for further development of research in this field. Despite existing research on project efficiency evaluation, the social efficiency problem is not sufficiently scientifically researched and described. Therefore, this research aims to contribute to filling the gap concerning a conceptualization of a social efficiency notion in management sciences, with particular emphasis on the field of project management. Achieving this goal may help to facilitate communication with the use of the social efficiency notion, further work related to operationalization of this concept and development methods for its measurement.

\section{Efficiency evaluation in project management}

Project management is a set of logically ordered activities (in accordance with the chosen management methodology), including planning, organizing, motivating and controlling, whose aim is to effectively and efficiently achieve multifaceted project goals. These activities (management functions) should form the basis for effective and efficient planning as well as implementing of management processes and projects. Planning means setting the organization's goals and determining effective ways of implementing them, i.e. assuming the maximization of the achieved effects and minimization of the expenditures incurred. Organizing is a logical grouping of activities and resources for the effective implementation of the objectives and tasks aimed at fulfilling them. The purpose of motivating and leading processes (managing people) is to create incentives for the members of the organization to effectively cooperate for the common interest of achieving the intended social effects and goals of the organization. In turn, controlling means critical observation of the organization's progress in effective implementation of its goals, comparing the results created with the previously adopted goals and taking possible corrective actions. Within each of these management functions, the structure of more detailed activities and tasks as well as the decision-making powers, responsibilities assigned to them are distinguished. It is also often the choice of how to act from the available set of potentially given variants.

Project management usually refers to long-term and complex socio-economic as well as research and development processes (e.g. from various technical fields). Over the years, one can observe an increase in the complexity of projects, which requires constant improvement of the level of professionalism in the management of advanced complex processes and projects. The greater complexity of advanced management processes increases the probability of failure and hinders the study of social efficiency, which is often not ranked 
first in importance in many organizations. An additional difficulty is the impact of external factors on the social effects achieved. Organizations implementing projects have direct influence on the efficiency of project management processes. However, they do not always have decisive influence on the values of social efficiency ratios. Therefore, on the one hand, obtaining appropriate social effects is difficult, and, on the other hand, their measurement is often complicated.

According to the sustainable development model, the planned effects of projects should be achieved through the use of market mechanisms while respecting social and environmental aspects. It is therefore necessary to plan and implement activities that should be, on the one hand, characterized by adequate economic efficiency, and, on the other hand, ensure the obtaining of appropriate social goals.

For example, in the case of European transport projects related to the construction of Green Transport Corridors, sustainable entrepreneurship activities are developed, and key performance indicators (KPIs) include supporting the creation of coherent entrepreneurial ecosystems for start-ups and existing SMEs. Economic and environmental KPI systems mainly focus on quantitative and physical aspects related, for example, to safety and compliance with ISO standards. Indicators for social performance, in turn, concern the measurement of such parameters as, for example, fluctuation by employee turnover, the sick leave rates of companies, temporary employees and workers numbers, and salary differences between the project stakeholders (Prause \& Hunke, 2014, p. 128).

KPIs identify factors that different types of commercial and non-commercial organizations should benchmark, compare, monitor and evaluate. Evaluation can be defined, according to Scriven (1991, p. 1), as a process of systematic estimation of the quality, value and worth of repeated actions and unique projects evaluated by means of interdisciplinary research based on approaches, methods and tools derived from different scientific disciplines, not only social sciences, but also economics, logics, management, politics, computer science and others.

Evaluation criteria of projects implemented by various types of organizations differ significantly and depend on the adopted commercial objectives or priorities written in the program documents in the case of public and development projects. These criteria concern, for example, efficiency, effectiveness, accountability, usefulness, relevance and long-term impact on the project implementation area. Among these many criteria, the one of socio-economic and environmental efficiency is usually of fundamental importance. Whereby, a significant part of this type of effects resulting from the implementation of projects is usually difficult to measure and has qualitative nature. In particular, social effects are hard to capture in the form of monetary values.

Estimating the financial effects of various types of projects does not pose such problems. Simple and discounted methods are well known, allowing for e.g. taking into account investment profitability, profit obtained by business or- 
ganizations and increase of their value. Measures of economic efficiency based on several economic values are universal, while various societies and communities are often characterized by significantly differentiated social values. Very different social values, expectations and customs can occur in societies and communities located in different countries or even among people from one country using different languages and professing different religions (Crafa et al., 2019). This is a significant challenge related to the development and application of methods for assessing the social effectiveness of projects that take into account social values subjectively understood by widely differentiated societies and communities.

Challenges related to the diverse understanding of social values are particularly evident in the case of development projects related to initiatives undertaken by the administration (government and self-government), various types of public institutions at local and regional level, and international organizations supporting pro-development activities (e.g. the European Union, United Nations Development Programme, World Bank, African Development Bank, United States Agency for International Development (USAID) and others.

Development projects have their own specificity, forcing the use of management methods adapted to them and multi-faceted evaluation of efficiency. They are usually implemented in poor countries and support people in unpaid form, their economic effects being less important. Such projects usually involve a large number of stakeholders, often with significant cultural, linguistic differences and attitudes towards their official duties (Diallo \& Thuillier, 2005). Building mutual trust, dealing with uncertainty and the complexity of social relations is the basis of success of all kinds of development projects, e.g. in transport sector (Szaruga et al., 2018).

In the context of a multidimensional evaluation of efficiency of the undertaken activities, organizations have problems with estimating the social impact regarding primary and secondary, positive and negative, mainly long-term social and environmental effects. Particularly, Social Impact Assessment (SIA) is frequently a strategic tool supporting the management of the social consequences of implemented development and public projects focused on building a sustainable biophysical and human environment (Wong \& Ho, 2015, p. 124).

In the literature on management sciences, there are positions on the issues concerning management and measuring the efficiency of various types of projects. Among them are, for example, considerations regarding project management methods for projects co-financed by EU funds (Kostalova et al., 2017), proposals for methods for evaluating the efficiency of public, investment, IT and other projects. In these publications, little attention is devoted to the issue of project social efficiency measurement. 


\section{Social efficiency of development projects}

Pro-development activities financed from public funds (often in the form of public and development projects) together with the effects resulting from free market influences have an impact on social well-being. In general, the assessment of public sector efficiency is carried out on two levels: macroeconomic and microeconomic. Social-related considerations at the macroeconomic level, and relating to the social, economic, cultural, political system as a whole, are to some extent present in the literature, such as Lefeber \& Vietorisz (2007). Among the methods and approaches used at this level, for example, Public Sector Efficiency (PSE) (Angelopoulos et al., 2008), Public Sector Performance (PSP) (Kaufmann et al., 2019) and Data Envelopment Analysis (DEA) can be mentioned, for example in Grmanova \& Pukala (2018).

A clear research gap concerning study related to the conceptualization of the notion of social efficiency at microeconomic level, planned and implemented development projects is noticeable. Approaches and methods used at this level are often transferred from the business environment and modified in terms of focusing on social effects. These types of solutions include social audit, Social Added Value (SVA) and Social Return on Investment (SROI).

Efficiency at the level of development projects is usually defined as the ratio of some results (effects) obtained to expenses and resources incurred. In the area of project management, the measurement of this parameter can concern realization of a comparative analysis and selection of the most profitable version of project from the analyzed set of alternative options (with the highest ratio of social results to expenses) or to the acceptance of some projects to implementation.

The social efficiency notion is associated with the concept of SIA. Both of them concern research on the processes of allocation of resources used and the assessment of interventions effects and development projects carried out as well as their impact on society at local and regional levels. Benefits and negative impact may be experienced by individuals, communities, organizations, etc. Comparative analyzes may refer to comparing conditions occurring after the implementation of development projects with the state before their commencement. They can also be implemented in relation to stakeholders whom development activities did not refer to. This type of research regards the estimation of the impact of implemented development projects on their stakeholders, social efficiency of using resources and measurement of the results obtained. Expenditures (costs) related to the implementation of development projects are usually easier to estimate in comparison with achieved social effects.

The difference in assessing social efficiency, as opposed to other types of efficiency measurement, is primarily related to the scope of intangible assets and barriers related to the need to estimate social effects that are difficult to calculate. The social efficiency factor can be determined by dividing the parameter of obtained social effects in a specified time by the expenses incurred during 
the project implementation. The above-mentioned social effects are difficult to estimate, among which, for example, the following could be identified: new jobs, impact on education, improvement of health protection and the quality of life, combating poverty, limiting social exclusion and others.

A definition of social efficiency of development projects can be formulated, which makes it possible to implement the conceptualization process, i.e. the transition from the social efficiency notion phase to the concept phase. The value of obtained social effects is the aggregation of positive and negative social effects of a development project, which can be expressed in monetary values or quantified using other non-monetary metrics (e.g. counted by using of social points). The idea of using social points in this case has been previously unknown in the literature and is introduced by the authors of this paper. It requires further analysis in separate, fundamental theoretical and practical considerations.

The general dependence on the determination of the social efficiency ratio may be as follows:

$$
S E I(t)=(S E(t)) /(C(t)),
$$

where:

SEI $(t)$ - social efficiency indicator in a specified time $t$;

$S E(t)$ - obtained positive social effects in a specified time $t$ (estimated using social points);

$C(t)$ - costs incurred by the development project in a specified time $t$.

Social efficiency evaluation processes are carried out in various ways, using not always properly selected methods that can ensure correct results. The lack of appropriate selection of methods may sometimes result from the deficiency of literature in the field of social efficiency evaluation, and organizations that sponsor projects and order evaluation often do not specify how to conduct evaluation processes and select convenient methods in this area (Parsons et al., 2019, pp. 114-123).

The results of research on social efficiency evaluation most often depend very much on the context of the research and the experience of those who implement it (Sagna, 2004, p. 14). These may prove the positive or negative effects obtained as a result of development projects realization and enable the implementation of learning systems based on formulated conclusions recorded in evaluation reports. The correctness of the research results obtained, and the quality of the conclusions are largely determined by the approaches, methods and evaluation tools used.

Among the most general approaches and models related to cost-benefit analyzes and measurement of social efficiency, one should mention the achievements of economics theorists whose work forms the basis for the subsequent development of methods and tools useful at microeconomic levels and development projects. The theoretical basis is undoubtedly connected with the achievements of Wilfred Pareto and his principle of allocation efficiency, the so-called Pareto optimum. According to this principle, in some sense the optimal solution 
is the one in which it is not possible to improve a system component without deteriorating another element. This is a very abstract and general approach that may be of limited use in research connected with studying efficiency of individual development projects and organizations on the ground of management sciences. Each project involves benefits for one group of stakeholders and negative effects or lack of positive changes in the case of other groups. A better basis for building models of social efficiency evaluation at the level of development projects is the Kaldor-Hicks approach, because according to it, the justification for the implementation of public and development projects may be social benefits that outweigh social costs (Wight, 2017). This approach allows to incorporate decisions associated with the increase of aggregate welfare, which is not possible in the case of assessment criteria based on Pareto approach (Kolb, 2018).

The assessment of the project's social efficiency is most often made with application of the SROI method, which allows inclusion of non-financial values related, for example, to the environmental or social impact of evaluated projects on stakeholders. This method aims to understand the social impact of public interventions, to support management and to report on the social value created by the organization (Millar \& Hall, 2013). The SROI value can be determined after identifying key stakeholders, defining the boundaries of social aspects for the conducted social efficiency assessment, applying the change theory to building the logical structure of evaluated projects and monetizing the social effects of development projects.

In order to measure accountability, social responsibility and the created social value, apart from SROI, auditing and social reporting are also used. They are not based on monetary values, do not allow to estimate the social return on investment and direct measurement of the social efficiency of projects. A similar situation takes place in the case of sustainable development reporting methods, which take into account aggregate economic, social and environmental values.

The Cost-Benefit Analysis (CBA), like SROI, is based on the use of monetary values to estimate the social benefits of the project. CBA is a very complicated method and aims rather to carry out a comprehensive evaluation of large projects. SROI is much simpler and more useful in assessing the social efficiency of development projects.

\section{Methods}

The following research methods were used in the presented research: publication analysis, bibliometric analysis, citation tracking, impact of publications, quantitative and qualitative analysis of publications from two most extensive scientific databases - Web of Science and Scopus. In the research carried out in April 2019 and concerning cited scientific literature, a search for 'social efficiency' topic and timespan 1998-2018 were used. 
This analysis was refined by the following Web of Science Categories management, business, economics, operations research management sciences, social sciences mathematical methods, social sciences interdisciplinary and development studies. The results of this analysis allow to formulate conclusions regarding the development of social efficiency research within selected scientific categories, as well as to identify the most important publications in this field of research.

\section{Results}

In total, 215 publications (related to management sciences, social sciences and economics) were found in Web of Science bases, which contain the notion 'social efficiency' in their title, abstract or keywords. There is clearly a research gap associated with a relatively small number of publications in this field - only 112 publications in management sciences (Grzeszczyk \& Pelszynski, 2019).

For 215 results from the Web of Science Core Collection databases, the following citation report details were noted: $\mathrm{h}$-index 23 (average citations per item 10.14), sum of times cited 2126 (without self-citations) and citing papers 2034 (without self-citations). There is an increase in the number of times cited per year parameter: from 1 in 1998 to 278 in 2018, which means a dynamic increase in interest in this field. The trend of the number of documents related to social efficiency notions and indexed in the Scopus database is also clearly growing. The subject area in this database was also limited to period 1998-2018 and related to management sciences, social sciences and economics.

One should be aware of the limitations of the methods used and, therefore, the imperfections of the results obtained. The analyzes carried out are simplified and based only on explorations of selected publications, which do not have to be the most reliable. The search areas have been narrowed down only to selected databases, and valuable publications may be located in other databases or outside such resources. The selected two most extensive scientific databases (Web of Science and Scopus) do not cover all publications that are important for the studied field. Further deepening and developing research with the use of bibliometric analyzes will make it possible to reduce the identified imperfections and obtain more objective results.

\section{Conclusions}

In the past, in management sciences, economic efficiency was a key criterion for assessing all types of activities undertaken by various types of organizations. This involved analyzing, first and foremost, the activities of profit-oriented enterprises. Over time, the research perspective has expanded to other types of organizations, and socially responsible enterprises as well as areas connected with sustainability, such as social, environmental, political and others. It has been noticed that acquiring economic efficiency cannot be the only goal and ef- 
ficiency notion has many meanings. Processes and projects undertaken by various organizations should be economically effective and at the same time being harmful to different social interests.

In general, the efficiency notion is associated primarily with economic sciences and there are difficulties in understanding it in social and management sciences research, and, in particular, in the area of project management. The presented research justifies the need for further study concerning social efficiency on the ground of management sciences. In particular, it states reason to develop it at the microeconomic level and in the field of management of development and public projects. This may be supported by realization of this paper goal and a conceptualization of a social efficiency notion.

Further literature research and bibliometric analysis could be beneficial for the development of theoretical achievements in the field of management sciences. The results of analyzes presented in this paper are only of preliminary character and require further development using more advanced bibliometric instruments. Research on selected areas within scientific disciplines, for example, the field of project management, would be particularly interesting.

Demonstrated in the course of conducted bibliometric analyzes, a significant increase in the number of times cited per year means the increase in the number of scientists involved in this field and the growth of its importance. Still, there is relatively little research on it, which indicates the existence of significant development potential. Study regarding the organization of the terminology relating to social efficiency evaluation should be continued. The approaches, methods and tools used in this field also require development and improvement.

Social efficiency is difficult to conceptualize and measure. Particularly challenging research tasks in this area are related to the estimation of social effects, which are often difficult to define unequivocally. These difficulties should not discourage further methodological study. Using social points, to estimate of social positive and negative effects, is one of the ideas worth in-depth analysis and study, for example, regarding new methods for assessing social efficiency of projects that can based on these points.

The presented study contributes to filling the gap concerning a conceptualization of a social efficiency notion in management sciences, with particular emphasis on the field of project management. Achieving the goal of this paper may facilitate communication in the scientific community using the social efficiency notion, exchange of scientific information, further work related to operationalization of this concept and development methods for its measurement. It would be desirable to develop new, proprietary methods of social efficiency evaluation that could be an important complement to existing methods. A particularly promising research area are methods that would not require the presentation of social effects in the form of monetary values. Potentially, they could enable a more objective evaluation, in comparison e.g. with SROI, which requires the monetization of social impact. 
It is worth carrying out further research related to this type of evaluation methods. The proposed methods should be characterized by practical utility, universality (ex-post, ongoing and ex-ante evaluation), and their usefulness should be examined using case studies of evaluation of various development projects implemented (e.g. by EU, USAID and others) in various countries characterized by a wide variation in social values.

One of the ideas worth considering might be exploring the possibility of using in this field a suitably adapted multicriteria analysis, which is undoubtedly a universal method and with great application possibilities in project evaluation. It makes it possible to study a significant number of aspects related to the evaluated projects, but it is a relatively low accuracy method of evaluating social efficiency. Therefore, it is worth considering its use together with other methods that will allow to get more accurate results.

\section{References}

Angelopoulos, K., Philippopoulos, A. \& Tsionas, E. (2008). Does public sector effi-ciency matter? Revisiting the relation between fiscal size and economic growth in a world sample. Public Choice, 137(1-2), doi:10.1007/ sl1127-008-9324-8.

Balcerzak, A.P., \& Pietrzak, M. (2015). Research and development expenditures and quality of life in European Union countries. Ekonomia i Prawo. Economics and Law, 14(3). doi:10.12775/EiP.2015.018.

Crafa, D., Liu, J., \& Brodeur, M.B. (2019). Social values and determinants of cultural fit in Quebec: the roles of ancestry, inguistic group, and mental health status. Frontiers in Psychology, 10. doi:10.3389/fpsyg.2019.00287.

Czaplak, J. (2016). Analysis of the effectiveness of public services provision by local governments in the years 2007-2013. Oeconomia Copernicana, 7(2). doi:10.12775/OeC.2016.014.

Diallo, A., \& Thuillier, D. (2005). The success of international development projects, trust and communication: an African perspective. International Journal of Project Management, 23(3). doi:10.1016/j.ijproman.2004.10.002.

Glodzinski, E. (2018). Project assessment framework: multidimensional efficiency approach applicable for project-driven organizations. Procedia Computer Science, 138. doi:10.1016/j.procs.2018.10.096.

Griffin, R.W. (2015). Fundamentals of management. Mason: South-Western Cengage Learning.

Grmanova, E., \& Pukala, R. (2018). Efficiency of insurance companies in the Czech Republic and Poland. Oeconomia Copernicana, 9(1). doi:10.24136/ oc. 2018.004 .

Grzeszczyk, T.A., \& Czajkowski, B. (2017). EU-funded project management in the context of suppliers and contractors selection. Procedia Engineering, 182. doi:10.1016/j.proeng.2017.03.181. 
Grzeszczyk, T.A., \& Klimek, D. (2018). The model of social innovation project evaluation. In J. Niu, \& Z. Wang (Eds.), Proceedings of the Asia-Pacific Social Science and Modern Education Conference. Shanghai: Atlantis Press. doi:10.2991/ssme-18.2018.26.

Grzeszczyk, T.A., \& Pelszynski, J. (2019). Unscrambling the concept of project social efficiency evaluation based on management sciences. In A.P. Balcerzak, \& I. Pietryka (Eds.), Proceedings of the 10th International Conference on Applied Economics Contemporary Issues in Economy: Entrepreneurship and Management. Olsztyn: Institute of Economic Research. doi:10.24136/ eep.proc.2019.4.

Jankalov, M., \& Jankal, R. (2017). The assessment of corporate social responsibility: approaches analysis. Entrepreneurship and Sustainability Issues, 4(4). doi:10.9770/jesi.2017.4.4(4).

Kaufmann, W., Taggart, G., \& Bozeman, B. (2019). Administrative delay, red tape, and organizational performance. Public Performance \& Management Review, 42(3). doi:10.1080/15309576.2018.1474770.

Kolb, R.W. (Ed.). (2018). The Sage encyclopedia of business ethics and society. Los Angeles: Sage.

Kostalova, J., Tetrevova, L., \& Patak, M. (2017). Project management methods in projects co-financed by EU funds. Engineering Economics, 28(3). doi:10.5755/j01.ee.28.3.13651.

Krajnakova, E., Navickas, V., \& Kontautiene, R. (2018). Effect of macroeconomic business environment on the development of corporate social responsibility in Baltic Countries and Slovakia. Oeconomia Copernicana, 9(3). doi:10.24136/oc.2018.024.

Lefeber, L., \& Vietorisz, T. (2007). The meaning of social efficiency. Review of Political Economy, 19(2). doi:10.1080/09538250701256672.

Millar, R., \& Hall, K. (2013). Social return on investment (SROI) and performance measurement: the opportunities and barriers for social enterprises in health and social care. Public Management Review, 15(6). doi:10.1080/147 19037.2012.698857.

Parsons, R., Everingham, J., \& Kemp, D. (2019). Developing social impact assessment guidelines in a pre-existing policy context. Impact Assessment and Project Appraisal, 37(2). doi:10.1080/14615517.2018.1485612.

Pashkevych, M., Kharchenko, M., \& Shishkova, N. (2018). Oval-sustainability in entrepreneurship. Open Economics, 1(1). doi:10.1515/openec-2018-0008.

Pavlova, I., \& Senfelde, M. (2017). The impact on the population on the sustainable urban economic development. Entrepreneurship and Sustainability Issues, 5(2). doi:10.9770/jesi.2017.5.2(12).

Prause, G., \& Hunke, K. (2014). Sustainable entrepreneurship along green corridors. Entrepreneurship and Sustainability Issues, 1(3). doi:10.9770/ jesi.2014.1.3(1). 
Sabini, L., Muzio, D., \& Alderman, N. (2019). 25 years of 'sustainable projects': what we know and what the literature says. International Journal of Project Management, 37(6). doi:10.1016/j.ijproman.2019.05.002.

Sagna, B.K. (2004). Cultural impact assessment project: framework for cultural impact assessment. Retrieved 19.12.2019 from http://dmeforpeace.org.

Scriven, M. (1991). Evaluation thesaurus. Newbury Park: Sage.

Suter, G.W., \& Cormier, S.M. (2008). A theory of practice for environmental assessment. Integrated Environmental Assessment and Management, 4(4). doi:10.1897/ieam_2008-004.1.

Szaruga, E., Skąpska, E., Załoga, E., \& Matwiejczuk, W. (2018). Trust and distress prediction in modal shift potential of long-distance road freight in containers: modeling approach in transport services for sustainability. Sustainability, 10(7). doi:10.3390/sul0072370.

Toledo, R.F. de, Miranda Junior, H.L., Farias Filho, J.R., \& Costa, H.G. (2019). A scientometric review of global research on sustainability and project management dataset. Data in Brief, 25. doi:10.1016/j.dib.2019.104312.

Wight, J.B. (2017). The ethics behind efficiency. The Journal of Economic Education, 48(1). doi:10.1080/00220485.2016.1252294.

Wong, C.H.M., \& Ho, W. (2015). Roles of social impact assessment practitioners. Environmental Impact Assessment Review, 50. doi:10.1016/j. eiar.2014.09.008.

\section{Acknowledgements}

Author contributions: authors have given an approval to the final version of the article. Authors contributed to this work as follows: T.A.G. (70\%) and J.P. (30\%) developed the concept and designed the study; T.A.G. (70\%) and J.P. (30\%) collected the data; T.A.G. $(80 \%)$ and J.P. (20\%) analysed and interpreted the data; T.A.G. (70\%) and J.P. (30\%) prepared draft of article; T.A.G. (80\%) and J.P. (20\%) revised the article critically for important intellectual content.

Funding: this research was funded by the Warsaw University of Technology, Faculty of Management sources.

Note: the results of this study were presented at 10th International Conference on Applied Economics Contemporary Issues in Economy (June 27-28, 2019, Torun, Poland). 